\title{
Delayed Treatment of Acute Subdural Hematomas: Retrospective Outcome Analysis of 215 Patients
}

\author{
Kanat Akhmetov ${ }^{1,2} \mathbb{D}$, Serik Akshulakov $^{2} \mathbb{D}$, Yerzhan Adilbekov ${ }^{2} \mathbb{D}$, Altynshash Jaxybayeva ${ }^{1}$, Mariya Dmitriyeva ${ }^{3 *}$ (D) \\ Medet Toleubayev ${ }^{3,4}$ (D) \\ ${ }^{1}$ Department of Neurology, Astana Medical University, Nur-Sultan, Kazakhstan; ${ }^{2}$ Department of Neurosurgery, National Center \\ for Neurosurgery, Nur-Sultan, Kazakhstan; ${ }^{3}$ Department of General and Plastic Surgery, Astana Medical University, Nur-Sultan, \\ Kazakhstan; ${ }^{4}$ Department of Surgery, Multidisciplinary City Hospital, Nur-Sultan, Kazakhstan
}

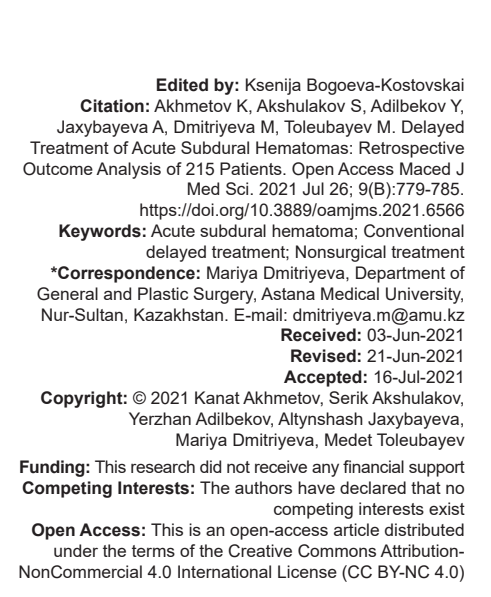

Abstract

BACKGROUND: The preferred treatment method for acute subdural hematoma (aSDH) is surgical intervention.

AIM: We aimed to show that, regardless of the good results of surgical treatment, conventional delayed treatment might be very useful in some situations and might lead to chronicity of hematoma as well as reduction of surgical intervention scope and reduce risk of anesthesia. It might also give rise to spontaneous resorption of hematoma.

METHODS: In the period March 1, 2013-March 1, 2020, we retrospectively examined 215 aSDH patients. The basic result of the outcome analysis was evaluated on the basis of the Glasgow Outcome Scale (GOS) at discharge after 3-month and 6-month follow-up.

RESULTS: A total of 215 patients with aSDH and minor or moderate brain injury were examined, while applying conventional delayed treatment, the following results were obtained: large craniotomy was carried out in 123 patients $(57.2 \%)$ on the $2^{\text {nd }}-3^{\text {rd }}$ day of observation, small craniotomy with drainage was applied in 29 patients $(13.5 \%)$ and spontaneous resorption of subdural hematoma occurred in 63 patients $(29.3 \%)$. The median score as per the Glasgow Coma Scale at admission to the hospital was 11.4.

CONCLUSION: This study showed that conventional delayed treatment applied in patients with aSDH and minor or moderate craniocerebral injury might lead to chronicity and resorption of aSDH. The outcomes as per the GOS scale also showed good data three and 6 months after hospitalization.

\section{Introduction}

Acute traumatic subdural hematoma (aSDH) is observed in $12-29 \%$ of patients with craniocerebral injury $(\mathrm{CCl})$ or craniocerebral trauma [1]. aSDH patients are often in a bad neurological state assessed with a score of 8 according to the Glasgow Coma Scale (GCS). Although the aSDH course largely varies, based on GCS, the death rate ranges from $30 \%$ to $60 \%$ in all aSDH patients and from $55 \%$ to $70 \%$ in patients with 8 or lesser score [2], [3], [4]. aSDH usually develops right after a severe injury, for example, after a traffic accident or after falling from a height; as a rule, aSDH presence and growth might elevate intracranial pressure to a dangerous level, leading to lethal outcomes [5], [6].

Current guiding principles prescribe urgent surgical treatment to patients who have $10 \mathrm{~mm}$ or wider hematoma or $5 \mathrm{~mm}$ or more midline shift shown on computerized tomography (CT) or to those who have intracranial pressure exceeding $20 \mathrm{~mm} \mathrm{Hg}$; these principles prescribe craniotomy with the removal of hematoma [7], [8], [9]. Based on research, it is apparent that the conventional treatment for aSDH might be used in some cases. Conventional delayed treatment is applied to asymptomatic hematomas, to patients refusing surgery, or to patients with high surgical risk. Any changeable factor that might help in ensuring a better post-surgical treatment result should be studied. A delayed surgical invasion will allow an acute clot to become a chronic one, delayed intervention would allow for acute clot to become chronic subsequently allowing for a smaller incision, smaller craniotomy (bure hole), less blood loss, and duration of anesthesia. A small craniotomy will ensure lesser blood loss and shorter anesthesia duration, thereby improving the outcome and reducing mortality [10]. Moreover, the delay might lead to spontaneous resorption of $\mathrm{aSDH}$.

To date, there is no consensus about the best treatment, as the treatment technique should be customized for each patient. Patients with symptoms and confirmed X-ray identification of hematomas are usually treated surgically, whereas patients with asymptomatic hematomas and small hematomas not taking a large space may be treated conventionally by means of medication or thorough observation. In this series, we report the case of 215 patients with aSDH surgical diagnosis and minor or moderate $\mathrm{CCl}$ who 
garnered 11-12 score as per GCS at admission and who underwent the primary course of conventional therapy, namely, monitoring of vital signs, CT monitoring, anesthesia, and anti-convulsion medication. Additional diagnostics and treatment were applied at the discretion of the neurosurgeons. It is worth reiterating that delayed intervention will allow an acute clot to become a chronic one, which will permit the creation of a small craniotomy (burr hole). A smaller craniotomy will ensure lesser blood loss and shorter anesthesia duration, as well as increase the chances of spontaneous resorption of aSDH.

\section{Data and Methods}

A number of cases were studied retrospectively, with this research aiming to identify all aSDH patients in the period March 1, 2013-March 1, 2020, at the National Scientific Center of Neurological Surgery of Nur-Sultan City, Kazakhstan. Using the international disease classification, $10^{\text {th }}$ review, and codes of current procedural terminology, all patients with aSDH diagnosis were identified. Inclusion criteria: Age of patients 18-90 years old, confirmed diagnosis of traumatic aSDH, mild or moderate grades of $\mathrm{CCI}$, GCS scores more than 9, CT thickness $<10 \mathrm{~mm}$, midline shift on CT $<7 \mathrm{~mm}$. The exclusion criteria: Age of patients $<18$ or older than 90 years, presence of $\mathrm{CSDH}$ on admission, the presence of non-traumatic SDH on admission, patients with associated intracranial hematomas (extradural hematoma, intracerebral, and intraventricular hemorrhage), severe $\mathrm{CCl}$, GCS scores $<9$, clot thickness on CT scan of more than $10 \mathrm{~mm}$, midline displacement on CT scan of more than $7 \mathrm{~mm}$. A total of $280 \mathrm{aSDH}$ diagnosed patients were admitted to the center over the period of the study. Decompressive craniotomy with removal of aSDH was performed in 65 patients within $24 \mathrm{~h}$ after admission. Up to 215 ( $n=215)$ patients were subjected to delayed treatment (conventional treatment, round-the-clock dynamic observation) and included in the final analysis.

For the 215 patients covered by the study, their clinical records were used to document sex, age, original injury date, surgery date, duration of delay time between injury and surgery, duration of hospitalization, primary symptoms at first scanning and before surgery including GCS at admission, post-surgical GCS, Glasgow Outcome Scale (GOS) at discharge (14 days after hospitalization) and 3- and 6-month GOS after discharge. All patients were subjected to a comprehensive examination, neurological examination, and brain CT scan. In performing the brain CT, the midline deviation, blood clot thickness was measured. When identifying subdural hematomas with volumes $<30 \mathrm{ml}$ in case of compensated patient state (11-12 score as per GCS), we applied delayed techniques of treatment. During the acute period, dynamic observation with conventional treatment was applied, including neuroprotective, pain-relieving, dehydrating therapy, anti-epileptic drugs, and antibacterial therapy. The criteria for surgical intervention, time prior to surgery and type of procedure were left to the discretion of the neurosurgical personnel on duty. If there are no contraindications, the standard practice at our institution is surgical removal in case of neurological examination data worsening or aggravation of symptoms such as headache and psychic state change, among others. Any movement deficit is, as a rule, the basis for immediate surgical invasion.

All procedures performed in studies involving human participants were in accordance with the ethical standards of the institutional and/or national research committee and with the 1964 Helsinki Declaration and its later amendments or comparable ethical standards (protocol №3 of Ethic committee of Nacional center for neurosurgery, Nur-Sultan city).

Descriptive statistics were used for the description of demographic and clinical characteristics of patient selection. We used Fisher's test for the quantitative assessment of relation between two category variables, particularly surgery type, surgery outcome, and treatment outcome. Regression logical analysis was carried out with the purpose of examining GOS at discharge and GOS after 3-month and 6-month follow-up and the relation thereof with demographic and clinical factors.

\section{Results}

\section{General demographic and clinical data}

Overall, 215 aSDH patients were included in the final analysis, 124 of whom were males $(57.7 \%)$ and 91 females (42.3\%). The average age was 41.4 years, with a range of 19 to 86 years (Figure 1). The injury in 117 patients $(54.4 \%)$ originated from traffic accidents; in 71 patients $(33 \%)$, the injury resulted from household accidents; in three patients $(1.4 \%)$, the injury was caused by occupational accidents; and in 24 patients $(11.2 \%)$, the cause of injury was not identified. The average time from the moment of injury until admission to the inpatient treatment facility was 1.76 days (within the range of $20 \mathrm{~min}$ to 6 days). The average duration of hospitalisation was 14 days within the range of 12-15 days (Table 1 ).

\section{Treatment methods}

All patients (215) were identified with 5-7-mm-thick aSDH or with midline shift exceeding. 


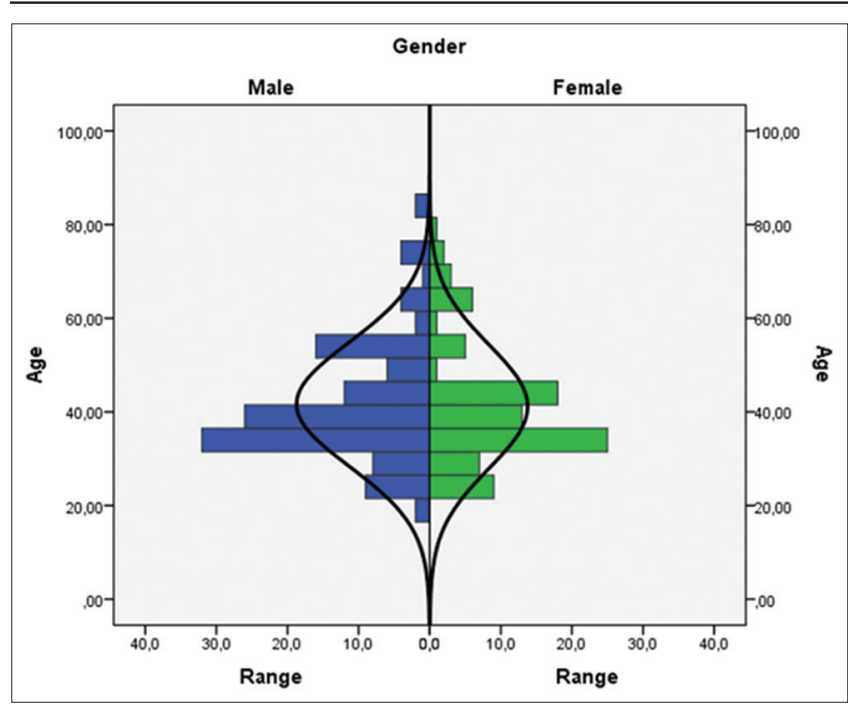

Figure 1: Gender and age distribution

$5 \mathrm{~mm}$ as per CT. The GCS score was 11-12. Delayed treatment, dynamic follow-up, neuroprotective drugs, pain-relieving medication, dehydration therapy, antibacterial therapy and therapy aimed at the prevention of convulsions were applied. Surgery on 152 out of 215 patients $(70.7 \%)$ was performed according to delayed techniques of treatment.

Table 1: General demographic and clinical data

\begin{tabular}{lll}
\hline & $\mathrm{n}$ & $\%$ \\
\hline $\begin{array}{l}\text { Gender } \\
\text { Male }\end{array}$ & 124 & 57.7 \\
Female & 91 & 42.3 \\
Age & median & range \\
\cline { 2 - 3 } & 41.4 & $19-86$ \\
\hline Mechanism of injury & $\mathrm{n}$ & $\%$ \\
\hline Traffic accident & 117 & 54.4 \\
Household accident & 71 & 33 \\
Occupational accident & 3 & 1.4 \\
Not identified & 24 & 11.2 \\
Period since the moment of injury & median & range \\
to hospital admission (days) & 1.76 & 20 min to 6 days \\
Average period of inpatient care & median & range \\
\cline { 2 - 3 } & 14 & \\
\hline
\end{tabular}

Of these patients, $123(57.2 \%)$ were subjected to decompressive craniotomy on the $2^{\text {nd }}-3^{\text {rd }}$ day due to their level of consciousness depression, which was scored 10 as per GCS or convulsive disorder. In 29 patients $(13.5 \%)$, in the course of delayed surgical treatment, the hematoma transformed into a chronic form. Due to this, minimally invasive surgery (closed external drainage of subdural hematoma) was performed on the $10^{\text {th }}-11^{\text {th }}$ day. Meanwhile, in 63 patients $(29.4 \%)$, unassisted resorption of subdural hematoma occurred on the $9^{\text {th }}-11^{\text {th }}$ day of follow-up (Table 2)

Table 2: aSDH patient treatment methods

\begin{tabular}{lll}
\hline Surgery & $\mathrm{n}$ & $\%$ \\
\hline Osteoplastic craniotomy (on the $2^{\text {nd }}-3^{\text {td }}$ day) & 123 & 57.2 \\
Closed external drainage (on the $10^{\text {th }}-11^{\text {th }}$ day) & 29 & 13.5 \\
Hematoma resorption (on the $9^{\text {th }}-11^{\text {th }}$ day) & 63 & 29.3 \\
\hline aSDH: Acute subdural hematoma. &
\end{tabular}

aSDH: Acute subdural hematoma.

Assessment as per Glasgow scale at admission and prior to surgery

The aSDH diagnosed patients to whom delayed treatment was applied were subjected to assessment of consciousness level. As per the Glasgow scale (GCS), 215 patients had an average score of 11.4 at admission. Prior to large craniotomy, the average score was 10.98. The patients with small craniotomy with external drainage showed an average score of 11.93, while the average score in the patients with spontaneous resorption of aSDH was 11.96 (Table 3).

Table 3: Assessment as per Glasgow scale at admission and during the course of treatment

\begin{tabular}{lll}
\hline GCS score & & \\
\hline Initial & median & range \\
\cline { 2 - 3 } & $(11.4 \pm 0.55)$ & $10-13$ \\
Prior to surgery & Median & range \\
\cline { 2 - 3 } Large craniotomy & $(10.98 \pm 0.25)$ & $10-12$ \\
Small craniotomy with drainage & $(11.93 \pm 0.25)$ & $11-12$ \\
On the $5^{\text {th }}$ day of observation in & median & range \\
\cline { 2 - 3 } patients not subjected to surgery & $(11.96 \pm 0.3)$ & $11-13$ \\
\hline GCS: Glasgow coma & &
\end{tabular}

\section{CT characteristics}

All patients had aSDH after primary CT examination. All patients (100\%) had an average of 5.96- $\mathrm{mm}$ midline shift according to CT and an average of $7.06 \mathrm{~mm}$ blood clot thickness. Based on the images right before surgery, the average midline shift was $6.06 \mathrm{~mm}$ and the average clot thickness was $7.17 \mathrm{~mm}$ in patients with large craniotomy; the average midline shift was $5.93 \mathrm{~mm}$ and the average clot thickness was $6.48 \mathrm{~mm}$ prior to small craniotomy with external drainage. At discharge (14 day), the CT of the patients with unassisted resorption of hematoma showed an average 5.04-mm midline shift and an average of $5.85-\mathrm{mm}$ clot thickness (Table 4). Figure 2 shows the CT images of the patients during follow-up.

\section{Table 4: CT characteristics of aSDH patients}

\begin{tabular}{|c|c|c|}
\hline \multirow[t]{2}{*}{ Right aSDH } & $\mathrm{n}$ & $\%$ \\
\hline & 159 & 73.9 \\
\hline Left aSDH & $\mathrm{n}$ & $\%$ \\
\hline At admission & $\begin{array}{l}56 \\
\text { median }\end{array}$ & $\begin{array}{l}26.1 \\
\text { range }\end{array}$ \\
\hline Midline shift (mm) & $(5.96 \pm 0.67)$ & $5-7$ \\
\hline Thickness (mm) & $(7.06 \pm 0.62)$ & $6-9$ \\
\hline Prior to osteoplastic craniotomy & median & range \\
\hline Midline shift (mm) & $(6.06 \pm 0.66)$ & $5-7$ \\
\hline Thickness (mm) & $(7.17 \pm 0.75)$ & $6-8$ \\
\hline Prior to external drainage of hematoma & median & range \\
\hline Midline shift (mm) & $(5.93 \pm 0.84)$ & $5-7$ \\
\hline Thickness (mm) & $(6.48 \pm 0.56)$ & $6-9$ \\
\hline $\begin{array}{l}\text { At discharge, the CT of patients with } \\
\text { unassisted resorption of hematoma }\end{array}$ & median & range \\
\hline Midline shift (mm) & $(5.04 \pm 0.21)$ & $5-6$ \\
\hline Thickness (mm) & $(5.85 \pm 0.53)$ & $5-7$ \\
\hline
\end{tabular}

\section{Glasgow outcome score analysis}

The GOS was examined in all patients at discharge and at 3- and 6-month follow-up.

The discharge GOS scores were as follows: GOS 5 for 99 (46\%), GOS 4 for 84 (39\%) patients, GOS 3 for $32(15 \%)$ patients, GOS 2 for 0 patient $(0 \%)$ and GOS 1 for 0 patient (0\%). The 3-month follow-up GOS scores were as follows: GOS 5 for 103 patients (48\%), GOS 4 for 99 patients (46\%), GOS 3 for 13 patients 


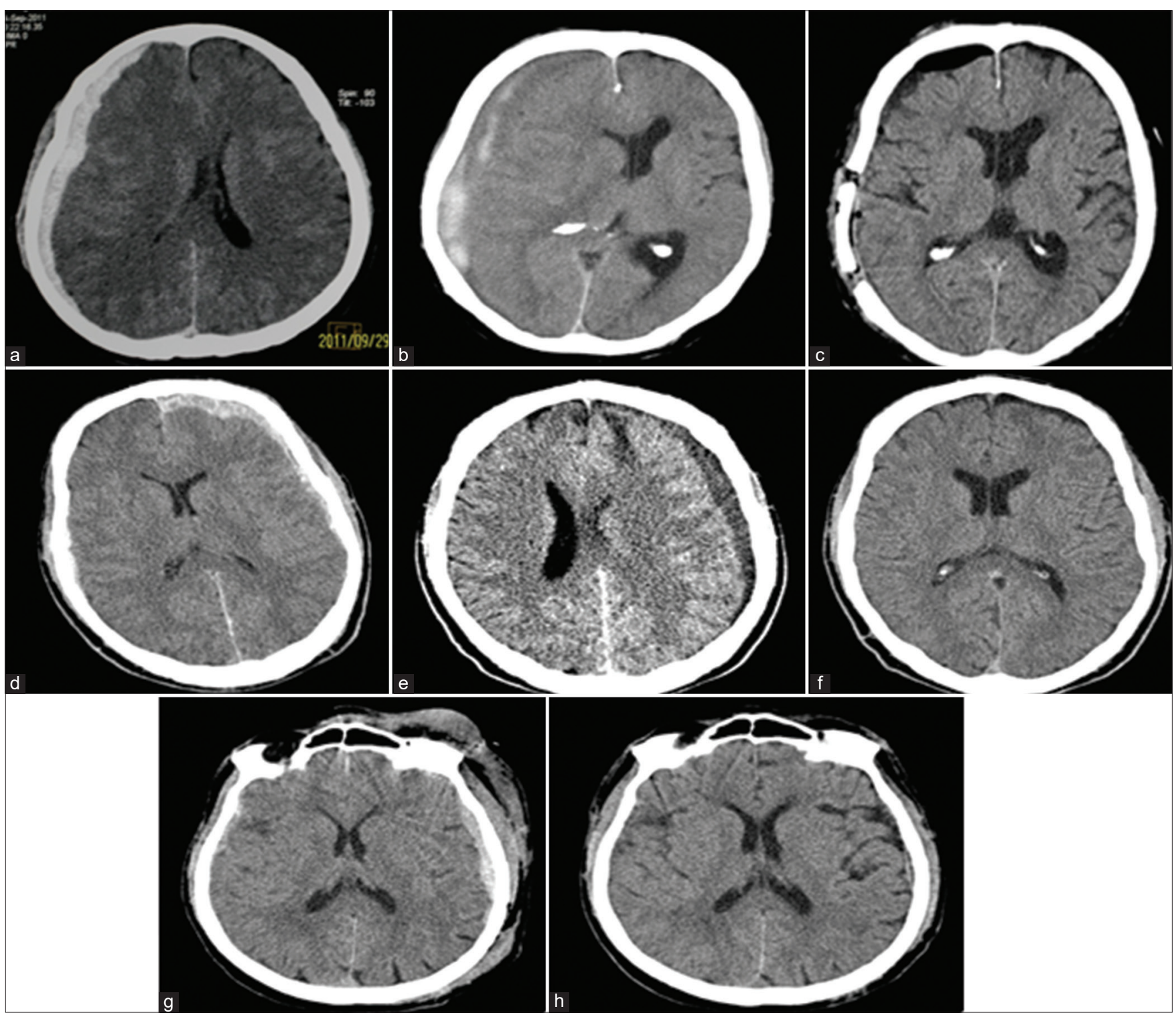

Figure 2: Computed tomography images of patients during follow-up. (a) Computed tomography (CT) prior to surgery; (b) CT on the $3^{\text {rd }}$ day; (c) CT after osteoplastic craniotomy; (d) CT prior to surgery; (e) CT on the $10^{\text {th }}$ day of observation; (f) CT on the $7^{\text {th }}$ day after closed external drainage of aSDH; (g) CT at admission; and (h) CT after unassisted resorption of hematoma on the $10^{\text {th }}$ day

(6\%), GOS 2 for 0 patients $(0 \%)$ and GOS 1 for 0 patients $(0 \%)$.

The 6-month follow-up GOS scores were as follows: GOS $4-5$ for 120 patients $(98.2 \%)$, GOS 3 for 4 patients $(1.8 \%)$, GOS 2 for 0 patient $(0 \%)$ and GOS 1 for 0 patient (0\%) (Figure 3, Tables 5-7).

Table 5: Discharge outcome

\begin{tabular}{|c|c|c|c|c|c|}
\hline \multirow[t]{2}{*}{ Score } & \multicolumn{2}{|l|}{ GOS 3} & \multicolumn{2}{|c|}{ GOS 4-5 } & \multirow[t]{2}{*}{$p$-value } \\
\hline & $\mathrm{n}$ & $\%$ & $\mathrm{n}$ & $\%$ & \\
\hline \multicolumn{6}{|l|}{ Gender } \\
\hline Male & 19 & 8.8 & 111 & 51.6 & 0.035 \\
\hline Female & 13 & & & 33.5 & \\
\hline \multirow[t]{3}{*}{ Age } & median & range & median & range & \\
\hline & $(40.9 \pm$ & $23-72$ & $(41.4 \pm$ & $19-86$ & 0.132 \\
\hline & 12.9) & & 12.9) & & \\
\hline Surgery & $\mathrm{n}$ & $\%$ & $\mathrm{n}$ & $\%$ & \\
\hline Large craniotomy (on the $2^{\text {nd }}-3^{\text {rd }}$ day) & 18 & 8.4 & 105 & 48.9 & $<0.001$ \\
\hline $\begin{array}{l}\text { Small craniotomy with drainage (on the } \\
10^{\text {th }}-11^{\text {th }} \text { day) }\end{array}$ & 9 & 4.2 & 20 & 9.3 & \\
\hline $\begin{array}{l}\text { Spontaneous resorption of hematoma } \\
\text { (on the } 9^{\text {th }}-11^{\text {th }} \text { day) }\end{array}$ & 5 & 2.3 & 58 & 27 & \\
\hline \multirow[t]{3}{*}{ Duration of hospitalisation } & median & range & median & range & \\
\hline & $(14.15 \pm$ & $12-15$ & $(14.03$ & $12-15$ & 0.001 \\
\hline & $0.72)$ & & $\pm 0.8)$ & & \\
\hline
\end{tabular}

Discussion

According to CT data, aSDH with a hemorrhage thicker than $10 \mathrm{~mm}$ and/or with a midline shift of $5 \mathrm{~mm}$ or more is considered to be an urgent surgical condition in accordance to standard recommendations; large Table 6: 3-month outcome

\begin{tabular}{|c|c|c|c|c|c|}
\hline \multirow[t]{2}{*}{ Score } & \multicolumn{2}{|l|}{ GOS 3} & \multicolumn{2}{|c|}{ GOS 4-5 } & \multirow[t]{2}{*}{$\mathrm{p}$-value } \\
\hline & $\mathrm{n}$ & $\%$ & $\mathrm{n}$ & $\%$ & \\
\hline \multicolumn{6}{|l|}{ Gender } \\
\hline Male & 7 & 3.3 & 117 & 54.4 & 0.106 \\
\hline Female & 6 & 2.8 & 85 & 39.5 & \\
\hline \multirow[t]{2}{*}{ Age } & median & range & median & range & \\
\hline & $\begin{array}{l}(39.4 \pm \\
11.8)\end{array}$ & $24-67$ & $\begin{array}{l}(41.5 \pm \\
13.1)\end{array}$ & $19-86$ & 0.380 \\
\hline Surgery & $\mathrm{n}$ & $\%$ & $\mathrm{n}$ & $\%$ & \\
\hline Large craniotomy (on the $2^{\text {nd }}-3^{\text {rd }}$ day) & 8 & 3.7 & 115 & 53.5 & $<0.001$ \\
\hline $\begin{array}{l}\text { Small craniotomy with drainage (on the } \\
10^{\text {th }}-11^{\text {th }} \text { day) }\end{array}$ & 1 & 0.5 & 28 & 13 & \\
\hline $\begin{array}{l}\text { Spontaneous resorption of hematoma } \\
\text { (on the } 9^{\text {th }}-11^{\text {th }} \text { day) }\end{array}$ & 4 & 1.9 & 59 & 27.5 & \\
\hline
\end{tabular}


craniotomy is required for the removal of subdural hematoma [11]. In any case, the CT data should correlate with clinical evidence in order to make the decision to perform an urgent surgery. In our research, we applied conventional delayed treatment to patients with aSDH and minor or moderate $\mathrm{CCl}$ and initial Glasgow scale score of 10-13. Delay in surgical intervention might reduce the grounds for a surgery in case of spontaneous resorption of aSDH. It may also reduce the surgical scope in case of the hematoma becoming chronic, reduce the risk of anaesthesia and reduce the possible complications of a surgery and its duration.

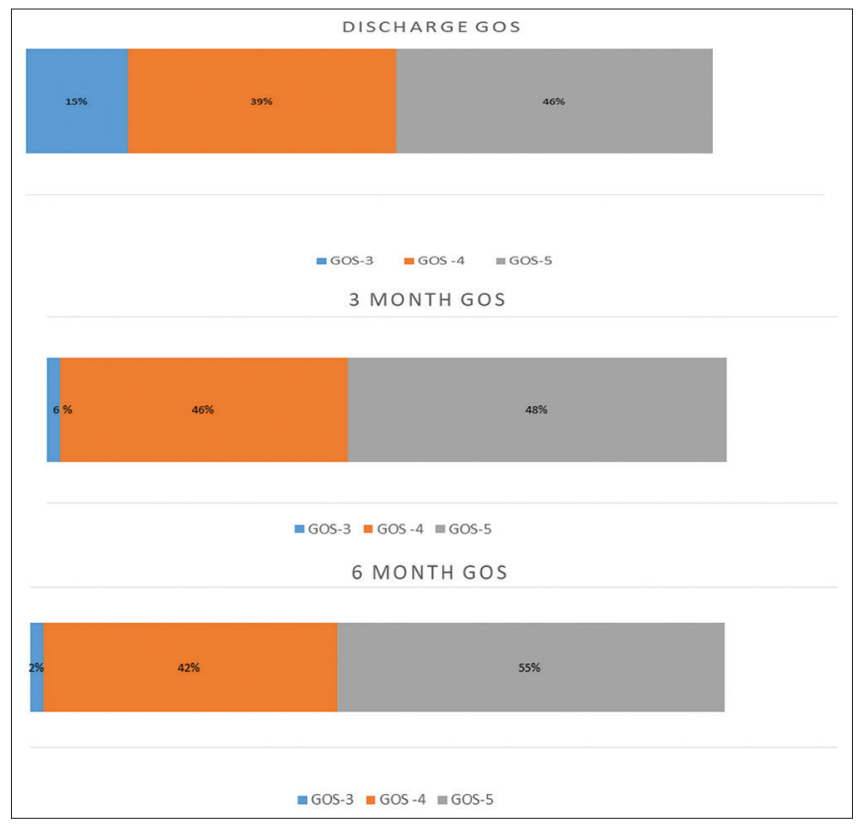

Figure 3: Distribution of GOS at discharge and at 3-month and 6-month follow-up. GOS: Glasgow outcome score

Kim et al.'s study showed that the surgery duration in aSDH patients is correlated with an increase in the number of complications [12]. Mathew et al. examined 23 aSDH patients (average GCS score of 14; range is 13-15) who were treated conventionally prior to hematoma becoming chronic, with the application of delayed closed drainage of hematoma with good results [13]. Moreover, Choi et al. published a series of 18 patients who were subjected to delayed removal

Table 7: 6-month outcome

\begin{tabular}{|c|c|c|c|c|c|}
\hline \multirow[t]{2}{*}{ Score } & \multicolumn{2}{|l|}{ GOS 3} & \multicolumn{2}{|c|}{ GOS 4-5 } & \multirow[t]{2}{*}{$p$-value } \\
\hline & $\mathrm{n}$ & $\%$ & $\mathrm{n}$ & $\%$ & \\
\hline \multicolumn{6}{|l|}{ Gender } \\
\hline Male & 1 & 0.5 & 123 & 57.1 & 0.037 \\
\hline Female & 3 & 1.4 & 88 & 41 & \\
\hline \multirow[t]{2}{*}{ Age } & median & range & median & range & \\
\hline & $(49.2 \pm$ & $34-67$ & $\begin{array}{l}(41.1 \pm \\
12.9)\end{array}$ & $19-86$ & 0.286 \\
\hline Surgery & $\mathrm{n}$ & $\%$ & $\mathrm{n}$ & $\%$ & \\
\hline $\begin{array}{l}\text { Large craniotomy (on the } \\
2^{\text {nd }}-3^{\text {rd }} \text { day) }\end{array}$ & 2 & 0.9 & 121 & 56.3 & $<0.001$ \\
\hline $\begin{array}{l}\text { Small craniotomy with drainage } \\
\text { (on the } 10^{\text {th }}-11^{\text {th }} \text { day) }\end{array}$ & 0 & 0 & 29 & 13.5 & \\
\hline $\begin{array}{l}\text { Spontaneous resorption of } \\
\text { hematoma (on the } 9^{\text {th }}-11^{\text {th }} \text { day) }\end{array}$ & 2 & 0.9 & 61 & 28.4 & \\
\hline
\end{tabular}

GOS: Glasgow Outcome Scale

Open Access Maced J Med Sci. 2021 Jul 26; 9(B):779-785 of aSDH, whereas $89 \%$ of their patients showed goods results at discharge (GOS 4-5) [14].

The conventional treatment of aSDH has become increasingly applicable, especially under the conditions of a minor $\mathrm{CCl}$. A number of studies have described the conventional treatment of patients as a good initial technique with subsequent delayed surgical decompression after the hematoma becomes chronic [12], [13], [14], [15]. There are research data available about the good results of conventional non-invasive treatment of aSDH patients not older than 65 years with GCS score over 8 [16].

Thus, for aSDH patients without strong lateralization signs and with almost normal GCS showing CT data of $\geq 5-\mathrm{mm}$ midline shift and/ or $\geq 10$-mm-thickness, there might be reasons for conventional non-invasive treatment in order to achieve unassisted resorption of hematoma or for a follow-up in an attempt to reduce surgical intervention and accompanying surgical risk related to a more extensive procedure. The abovementioned also depends on the availability of a facility, where a thorough neurological observation can be carried out [17].

Our study included aSDH patients with initial average GCS score of 11.4 (interval of 10-13) and average CT data of $5.96-\mathrm{mm}$ midline shift and $7.06-\mathrm{mm}$-thick clot. The average age of the patients was 41.4 years. We applied delayed techniques of treatment, over the course of which 63 (29.3\%) out of 215 aSDH patients achieved spontaneous resorption of hematoma as a result of delayed treatment. From the result of follow-up, the aSDH of 29 (13.5\%) patients transformed into chronic form (cSDH) with delayed small craniotomy (burr hole) on the $10^{\text {th }}$ day after admission, while 123 patients $(57.2 \%)$ had to undergo large craniotomy due to health state aggravation on the $2^{\text {nd }}-3^{\text {rd }}$ day of follow-up.

As far as outcome is concerned, $85 \%$ of the patients had a GOS of 4-5 at discharge, $94 \%$ had a GOS of $4-5$ at 3 months after discharge and $98 \%$ had a GOS of 4-5 after 6-months follow-up.

Comparing our results of delayed surgical intervention at discharge, $8.4 \%$ of the patients subjected to large craniotomy had a GOS of 3 in comparison with $9 \%$ of patients after bur hole craniotomy and $5 \%$ of patients after spontaneous resorption of hematoma. The patients who underwent delayed surgery showed a GOS of 4-5 at discharge in $48.9 \%$ of cases in comparison with $9.3 \%$ of patients after bur hole craniotomy and $27 \%$ of patients after spontaneous resorption of hematoma. The average number of days spent at the inpatient care facility was $12-15$. The mortality rate at discharge was $0 \%$.

This research has the following limitations. The study is retrospective, so there is no monitoring group involved. Our study also included patients with minor and moderate brain injury, which possibly led to a high percentage of spontaneous resorption of subdural hematoma. 
Thus, the application of delayed and minimally invasive treatment leads to a more favorable outcome, especially in the category of patients with minor $\mathrm{CCl}$ and aSDH. This might facilitate a quicker recovery and reduction of disability risk. Modern methods of treatment, risk factors, and results of conventional treatment of aSDH might constitute a valuable body of knowledge in the application of conventional strategies of aSDH patient treatment.

\section{Conclusion}

This study has shown that conventional delayed treatment yields good results in patients with aSDH and minor or moderate $\mathrm{CCl}$. These strategies might lead to chronicity of subdural hematoma and delayed small craniotomy, as well as spontaneous aSDH resorption, in the given category of patients. The outcomes at 3 and 6 months after hospitalization also showed good results.

\section{Acknowledgment}

The authors thank all of the staff members of the National Scientific Centre of Neurosurgery of Kazakhstan for their assistance while this study was being conducted.

\section{Consent for Publication}

The results of the analysis were solely based on the previously published literature, as this study did not involve patients or public.

\section{References}

1. Frontera JA, Egorova N, Moskowitz AJ. National trend in prevalence, cost, and discharge disposition after subdural hematoma from 1998-2007. Crit Care Med. 2011;39(7):161925. https://doi.org/10.1097/ccm.0b013e3182186ed6 PMid:21423002

2. Karibe H, Hayashi T, Hirano T, Kameyama M, Nakagawa A, Tominaga T. Surgical management of traumatic acute subdural hematoma in adults: A review. Neurol Med Chir. 2014;54(11):88794. https://doi.org/10.2176/nmc.cr.2014-0204

PMid:25367584
3. Leitgeb J, Mauritz W, Brazinova A, Janciak I, Majdan M, Wilbacher I, et al. Outcome after severe brain trauma due to acute subdural hematoma. J Neurosurg. 2012;117(2):324-33. https://doi.org/10.3171/2012.4.jns 111448 PMid:22631691

4. Wilberger JE Jr., Harris M, Diamond DL. Acute subdural hematoma: Morbidity, mortality, and operative timing J Neurosurg. 1991;74(2):212-8. https://doi.org/10.3171/ jns.1991.74.2.0212

PMid:1988590

5. Howard MA, Gross AS, Dacey RG Jr., Winn HR. Acute subdura hematomas: An age-dependent clinical entity. J Neurosurg. 1989;71(6):858-63. https://doi.org/10.3171/jns.1989.71.6.0858 PMid:2585078

6. Taylor CA, Bell JM, Breiding MJ, Xu L. Traumatic brain injuryrelated emergency department visits, hospitalizations, and deaths-United States, 2007 and 2013. MMWR Surveill Summ. 2017;66(9):1-16. https://doi.org/10.15585/mmwr.ss6609a1 PMid:28301451

7. Gaonkar VB, Garg K, Agrawal D, Chandra PS, Kale SS. Risk Factors for progression of conservatively managed acute traumatic subdural hematoma: A systematic review and metaanalysis. World Neurosurg. 2021;146:332-41. https://doi. org/10.1016/j.wneu.2020.11.031

PMid:33197632

8. Phan K, Moore JM, Griessenauer C, Dmytriw AA, Scherman DB, Sheik-Ali S, et al. Craniotomy versus decompressive craniectomy for acute subdural hematoma: Systematic review and meta-analysis. World Neurosurg. 2017;101:677-85.e2. https://doi.org/10.1016/j.wneu.2017.03.024

PMid:28315797

9. Lukasiewicz AM, Grant RA, Basques BA, Webb ML, Samuel AM, Grauer JN. Patient factors associated with 30-day morbidity, mortality, and length of stay after surgery for subdural hematoma: A study of the American college of surgeons national surgical quality improvement program. J Neurosurg. 2016;124(3):760-6. https://doi. org/10.3171/2015.2.jns 142721 PMid:26315000

10. Akbik OS, Starling RV, Gahramanov S, Zhu Y, Lewis J. Mortality and functional outcome in surgically evacuated acute subdural hematoma in elderly patients. World Neurosurg. 2019;126:e123541. https://doi.org/10.1016/j.wneu.2019.02.234 PMid:30885866

11. Bullock MR, Chesnut R, Ghajar J, Gordon D, Hartl R, Newell DW, et al. Surgical management of acute subdural hematomas. Neurosurgery. 2006;58 Suppl 3:16-24; discussion Si-iv. https://doi.org/10.1227/01.neu.0000210364.29290.c9 PMid: 16710968

12. Kim BD, Hsu WK, de Oliveira GS Jr., Saha S, Kim JY. Operative duration as an independent risk factor for postoperative complications in single-level lumbar fusion: An analysis of 4588 surgical cases. Spine (Phila Pa 1976). 2014;39(6):510-20. https://doi.org/10.1097/brs.0000000000000163

PMid:24365901

13. Mathew P, Oluoch-Olunya DL, Condon BR, Bullock R. Acute subdural haematoma in the conscious patient: Outcome with initial non-operative management. Acta Neurochir (Wien). 1993;121(3-4):100-8. https://doi.org/10.1007/bf01809258 PMid:8512003

14. Choi YH, Han SR, Lee CH, Choi CY, Sohn MJ, Lee CH. Delayed burr hole surgery in patients with acute subdural hematoma: Clinical analysis. J Korean Neurosurg Soc. 2017;60(6):717-22. https://doi.org/10.3340/jkns.2017.0404.010

PMid:29142632 
15. Croce MA, Dent DL, Menke PG, Robertson JT, Hinson MS Young $\mathrm{BH}$, et al. Acute subdural hematoma: Nonsurgical management of selected patients. J Trauma. 1994;36(6):820-6. https://doi.org/10.1097/00005373-199406000-00012

\section{PMid:8015004}

16. Feliciano $\mathrm{CE}$, de Jesus $\mathrm{O}$. Conservative management outcomes of traumatic acute subdural hematomas. P R Health Sci J.
2008;27(3):220-3.

PMid: 18782966

17. Leung GK, Ng GK, Ho W, Hung KN, Yuen WK. Impact of a multidisciplinary trauma team on the outcome of acute subdural haematoma. Injury. 2012;43(9):1419-22. https://doi. org/10.1016/j.injury.2011.03.017

PMid:21474130 